\title{
Successful closure of a colon perforation via the over-the-scope-clip system after accidental ingestion of a fish bone
}

Bowel perforation due to accidental ingestion of foreign bodies is rare, and large-bowel perforation is rarer [1]. An 87-year-old man was admitted for removal of a foreign body in the colon, which was detected incidentally on computed tomography (CT) following penetration of the sigmoid colon ( $\triangleright$ Fig. 1 ). The foreign body was not detected on radiography. As the patient had no symptoms or abdominal rigidity, we planned to remove the foreign body endoscopically ( $>$ Video 1 ).

On endoscopy, the foreign body was identified to be a fish bone with a sharp end; the point of penetration corresponded with its sharp end ( Fig.2). We pulled the bone in the oral direction and removed it using grasping forceps. After removal, a deep ulcer formed following mucosal edema ( $\triangleright$ Fig.3). We decided to close the ulcer using the over-thescope-clip (OTSC) system (Ovesco Endoscopy AG, Tübingen, Germany), as regular clipping was not possible. Endoscopic double-grasping forceps ("twin- grasper") could not grasp the tissue because the ulcerated area was too inflamed and friable. Eventually, we suctioned and pulled the colon mucosa into the hood of the OTSC system, focusing on the central point of penetration. The OTSC was applied and successfully closed the perforation ( $\mathbf{F i g} \cdot \mathbf{4})$. CT showed the metal clip in the sigmoid coIon and no complications ( $\mathbf{F i g . 5}$ ). The patient was thus treated conservatively. Accidental ingestion of foreign bodies is a common reason for hospital visits. If the foreign body is sharp, as with the fish bone, the penetration is generally $15 \%-35 \%$ deep [2]. For colon perforations, the OTSC has been shown to be comparable to surgical closure in an animal model [3]. Even for acute gastrointestinal wall defects in humans, such as nonsurgical perforations and postoperative anastomotic leaks or perforations, the OTSC has been reported to be effective in $>75 \%$ of patients [4].

Endoscopy_UCTN_Code_CCL_1AD_2AH

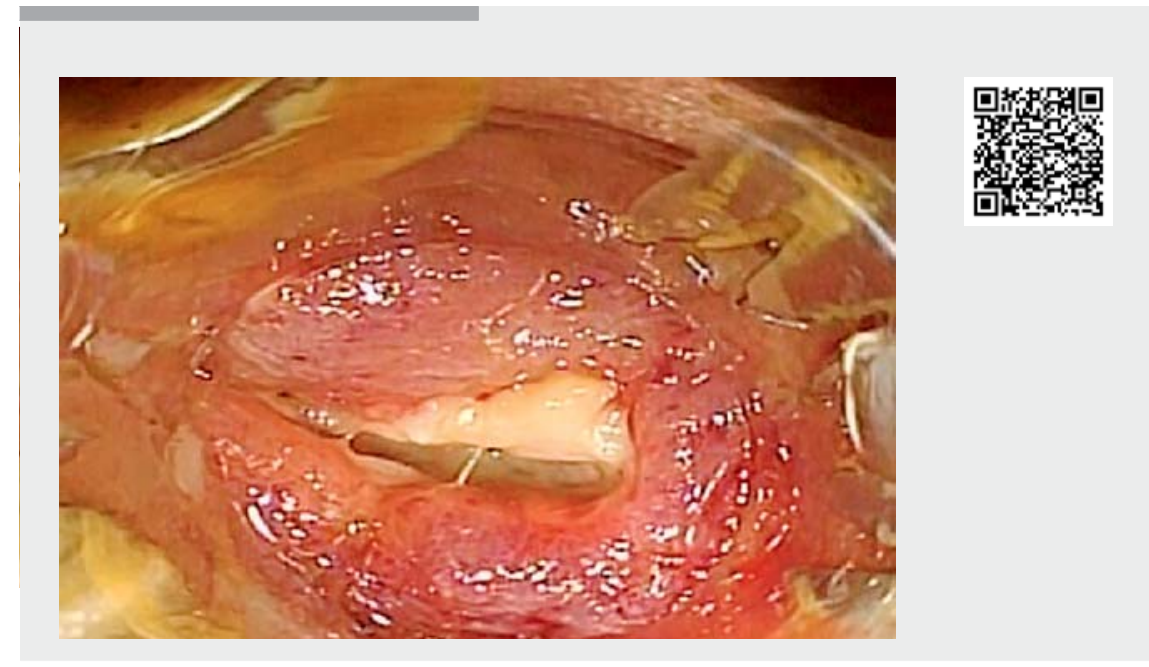

$\checkmark$ Video 1 The foreign body was identified to be a fish bone in the sigmoid colon. The point of penetration corresponded with the sharp end of the bone. The fish bone was removed using grasping forceps. The perforation was successfully closed using an over-thescope-clip.

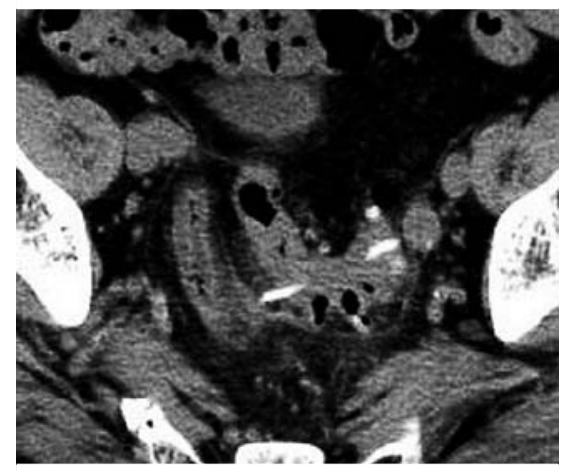

- Fig. 1 Computed tomography scan showed the colon wall perforated by the foreign body.

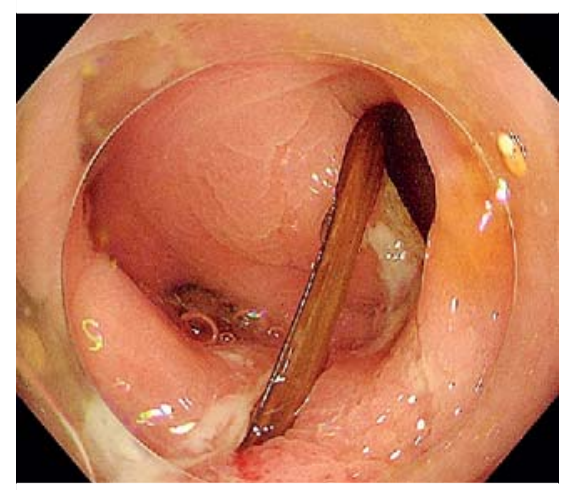

- Fig. 2 Endoscopically identified foreign body. The point of penetration corresponded with the sharp end of the foreign body.

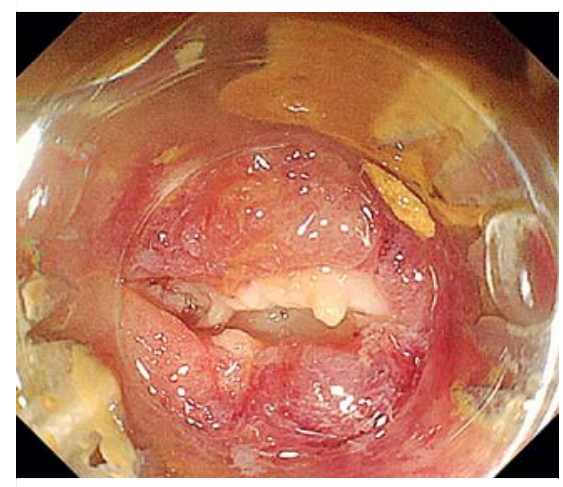

- Fig. 3 After removal of the foreign body, a deep ulcer developed following mucosal edema. 


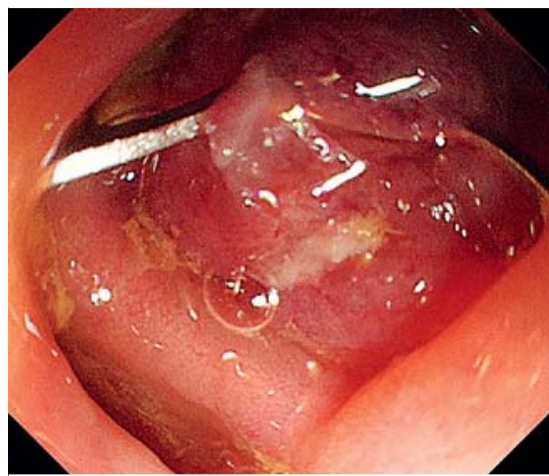

- Fig. 4 The point of penetration was closed with a metal clip using an over-thescope-clip system.

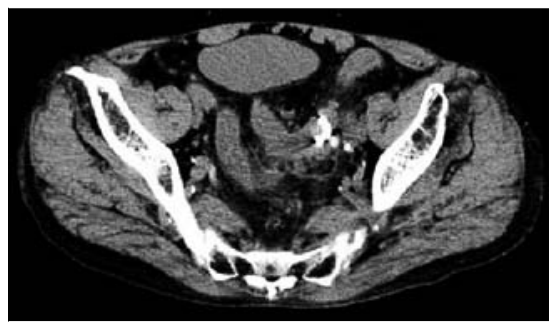

Fig. 5 Computed tomography scan showed the metal clip in the sigmoid colon, and no complications.
Competing interests

None

The authors

Tsuyoshi Suda', Shingo Soga ${ }^{2}$, Naoki Oishi ${ }^{1}$, Takuya Seike ${ }^{1}$, Koichi Hirose ${ }^{2}$

1 Department of Gastroenterology, Kanazawa Municipal Hospital, Kanazawa Ishikawa, Japan

2 Department of Surgery, Kanazawa Municipal Hospital, Kanazawa, Ishikawa, Japan

\section{Corresponding author}

\section{Tsuyoshi Suda, MD}

Department of Gastroenterology, Kanazawa Municipal Hospital, 3-7-3, Heiwamachi, Kanazawa, Ishikawa 921-8105, Japan Fax: +81-76-2452690

t.suda1112@gmail.com

\section{References}

[1] Khadda S, Yadav AK, Ali A et al. A rare case report of sigmoid colon perforation due to accidental swallowing of partial denture. Indian J Surg 2015; 77: 152-154

[2] Henderson CT, Engel J, Schlesinger P. Foreign body ingestion: review and suggested guidelines for management. Endoscopy 1987; 19: 68-71
[3] von Renteln D, Schmidt A, Vassiliou MC et al. Endoscopic closure of large colonic perforations using an over-the-scope clip: a randomized controlled porcine study. Endoscopy 2009; 41: 481-486

[4] Raithel M, Albrecht H, Scheppach W et al. Outcome, comorbidity, hospitalization and 30-day mortality after closure of acute perforations and postoperative anastomotic leaks by the over-the-scope clip (OTSC) in an unselected cohort of patients. Surg Endosc 2017; 31: 2411-2425

\section{Bibliography}

DOI https://doi.org/10.1055/a-1024-3373

Published online: 25.10.2019

Endoscopy 2020; 52: E126-E127

(c) Georg Thieme Verlag KG

Stuttgart · New York

ISSN 0013-726X

\section{ENDOSCOPY E-VIDEOS}

https://eref.thieme.de/e-videos

口回 Endoscopy E-Videos is a free Fection, reporting 回: on interesting cases and new techniques in gastroenterological endoscopy. All papers include a high quality video and all contributions are freely accessible online.

This section has its own submission website at

https://mc.manuscriptcentral.com/e-videos 